\title{
PSYCHOTHERAPY IN MIGRAINE
}

BY RICHARD A. HUNTER, M.D., M.R.C.P., D.P.M.

AND

IAN P. ROSS, M.D., M.R.C.P. Formerly Assistant Registrar

National Hospitals for Nervous Diseases, Queen Square, London

In a neurological out-patient department a number of patients complaining of migrainous headaches unassociated with physical disease show little or no response to drugs and tend to become regular attenders. Dissatisfied with this frustrating situation, we decided on a combined approach to ascertain, firstly, to what extent, if any, psychological factors were playing a part ; and, secondly, the value of treatment on psychotherapeutic lines. Patients were examined for the presence of physical conditions usually held to precipitate or aggravate migraine; after which they were investigated and treated psychiatrically. Here we present observations and results on 35 patients followed up for a period of 6 to 12 months.

\section{Materials and Methods}

The diagnosis of migraine was made when patients complained of paroxysmal headaches, usually unilateral, associated with nausea and vomiting, often preceded by visual disturbances and, less commonly, by other focal symptoms, and followed by a period of exhaustion. All patients had been referred for specialist advice because attacks were persisting or becoming increasingly severe, causing incapacity for work and emotional disturbance, despite standard migraine treatments in various combinations and doses. Only patients with a history longer than two years were included, in order to provide an adequate background against which both severity and results could be assessed. Other patients excluded were those with suspected cerebral tumour or angioma and those with severe hypertension, as well as patients with obvious psychogenic headaches without the characteristics of migraine.

Eight patients fulfilled all conditions but did not complete the minimum period of follow-up and are omitted from the series. Two of them were seen only once; one, a schizophrenic, was shortly afterwards admitted to a mental hospital ; the other a boy of 12 , whose anxious mother had taken him to a number of other hospitals. Two patients left London, four stopped attending after two to three months, one had previously been to a mental hospital, and one lived under severe domestic strain. The other two, one of whom was taking pethidine regularly, were reluctant to accept any treatment other than continuation of large quantities of drugs to which they had been accustomed.

The following procedure was adopted. First, a full formal history, with special reference to headache, associated symptoms, drug habits, and social and domestic circumstances, was taken, followed by a general and neurological examination. Particular attention was paid to evidence of disease of the nervous system, refractive errors, sinus infection, allergic disorders, gastro-intestinal disturbances, cardiovascular disease, and endocrine abnormalities. All patients had their urine analysed and plain radiographs of the skull were taken; other investigations were done where necessary-for example, blood count, E.S.R., Wassermann reaction, blood urea, etc.-or patients were referred to special departments such as E.E.G. and E.N.T. Patients were then seen psychiatrically, and subsequently were followed at monthly or six-weekly intervals by both of us. We gave no physical treatment, and though patients were not made to stop drugs they were already taking they were advised to reduce them to a minimum.

Of the 35 patients, 20 were women and 15 men; their ages ranged from 21 to 59 . Sixteen women were housewives, eight were in part-time or full-time employment varying from charwoman to model; and four were unmarried whole-time workers-a factory worker, a clerk, a civil servant, and a dietitian. The occupations of the men varied from unskilled labourer to manager of a large manufacturing concern.

\section{History}

Twelve women and six men gave a history of migrainous headaches in a parent or sibling. Two women and two men gave a history of mental illness in a parent. The father of one woman committed suicide; she herself had received mental-hospital treatment for depression, was married to a transvestite, and had a backward child. One man had a mongol child.

Their previous histories of physical diseases were without significance. Apart from childhood ailments two women had had a hysterectomy, one a thyroidectomy, two toxaemia of pregnancy, one nephritis, one typhoid, one a prolapsed lumbar intervertebral disk; two men had had tuberculosis. Three patients gave a history of head injury; in two this was mild, and in the one in which it was moderately severe it preceded the onset of migraine by 15 years.

In their previous psychiatric history four women had had a depressive illness necessitating treatment; six volunteered that they had always been " nervy," anxious, easily upset, and inclined to worry excessively ; and one had a persistent facial hemispasm after a bomb incident. Of the men, four were self-confessed " nervous types," one had a compensation neurosis, and one a history of bouts of excessive drinking.

\section{Associated Physical Conditions}

In all cases careful inquiry was made for possible physical factors causing or aggravating headaches. No patient had associated epilepsy. Electroencephalography was performed on eight patients: in four the record was normal ; in one doubtfully abnormal ; two had a mild generalized non-specific abnormality; and one had doubtfully lateralizing features which had remained unchanged for three years.

Ocular Abnormalities.-Of the 35 patients, 25 had had their eyes tested and 14 wore spectacles. None had ocular disease and none noticed any improvement in migraine from correction of refractive errors.

Diseases of Ear, Nose, and Throat.-Two patients gave a history of chronic sinus trouble, one of whom had had operative treatment ; both thought it unrelated to their headaches. Two other patients were found to have infection of the maxillary or frontal sinus causing mild symptoms unrelated to their migraine. In one patient the chance finding of a small osteoma in a frontal sinus was thought to be incidental. 
Allergy.-Two patients gave a history of allergic disorders before the onset of migraine. None had evidence of allergic skin diseases, rhinitis, or asthma at the time of examination.

Gastro-intestinal Abnormalities.-One man had occasional diarrhoea as a result of recurrent dysentery but noticed no relation with his migraine; one had a history of alternating dyspepsia and migraine, and subsequently developed a gastric ulcer with relief of migraine; another had recurrent bouts of dyspepsia unrelated to migraine without radiological abnormality. Most patients reported anorexia and gastric upsets with their headaches. None noticed that migraine followed any particular article of diet.

Cardiovascular Disease.-Mild hypertension without cardiovascular hypertrophy was found in two patients and was regarded as incidental. As stated before, patients with severe hypertension with sustained diastolic pressures of $120 \mathrm{~mm}$. $\mathrm{Hg}$ were excluded. One man had developed angina of effort after many years of migraine.

Endocrine Disturbance.-No patient had evidence of major endocrine upset.

Other Conditions.-Two patients had a mild anaemia, one chronic bronchitis, and one cervical spondylosis.

\section{Duration of Migraine}

Many patients had had headaches which in the course of time became more severe and assumed the characteristics of migraine; in them the transition from one to the other was hard to establish precisely, as was the exact year of onset in patients with a long history. Some of the following figures are therefore only approximations.

The duration of migraine varied from 3 to 37 years, with an average of $11 \frac{1}{2}$ years. Of the women, four had had migraine for five years or less ; 10 for 6-10 years ; two for 11-15 years; and one each for 18, 20, 30, and 37 years. Nine women had a history of headaches or bilious attacks in childhood followed by an interval of freedom before migraine developed. Most gave a history of insidious onset with gradually increasing severity and frequency. Only in two was the onset sudden. Six men had had migraine for five years or less ; five for 6-10 years; and one each for $11,16,17$, and 18 years. Only one man gave a history of having suffered from headaches in childhood which gradually became migrainous; one had headaches in his twenties, which ceased, only to begin again as migraine in his fifties; and two gave a history of sudden onset. Table I gives the age at onset in relation to presenting age.

\begin{tabular}{|c|c|c|c|c|}
\hline \multirow{3}{*}{ Age } & \multicolumn{4}{|c|}{ Number of Patients } \\
\hline & \multicolumn{2}{|c|}{ Age at Onset } & \multicolumn{2}{|c|}{ Presenting Age } \\
\hline & F. & M. & F. & M. \\
\hline \multirow[t]{2}{*}{$\begin{array}{l}11-20 \\
21-30 \\
31-40 \\
41-50 \\
51+\end{array}$} & $\begin{array}{l}7 \\
7 \\
4 \\
1 \\
1\end{array}$ & $\begin{array}{l}5 \\
4 \\
4 \\
1 \\
1\end{array}$ & $\begin{array}{l}-4 \\
7 \\
7 \\
2\end{array}$ & $\begin{array}{l}-4 \\
8 \\
1 \\
2\end{array}$ \\
\hline & 20 & 15 & 20 & 15 \\
\hline
\end{tabular}

\section{Features of the Attack}

All 35 patients gave a history of paroxysmal headache, frequently unilateral but not confined to one or other side. All complained of nausea; some vomited with most attacks, some only rarely. Fourteen had at one time or another characteristic visual disturbances; four had focal disturbances - two of speech and two face and limb paraesthesiae. Other common symptoms were malaise, dizziness or muzziness, inability to concentrate, insomnia, etc. All patients were having at least one attack a week, many two or three or even more.

The duration of headache varied from an hour to several days; or they might follow in quick succession without interruption for weeks. Between attacks many complained of daily or even continuous headache and heaviness of the head or other anomalous and at times bizarre sensations. Often headaches which were migrainous at onset persisted as indefinite and dull pains, equally distressing because of their duration. Patients who were well between infrequent and isolated attacks were not seen in this series.

Of the 13 women who had borne children, nine were free from attacks during pregnancy. Two women had migraine mostly with periods; while four noted occasionally that they were worse at this time, and one that she was better. There was no clear relation to the menopause. Of the five women past the menopause one was improved, three were unchanged, and one was worse.

\section{Incapacity}

An attempt was made to assess to what extent patients were incapacitated (Table II). All patients were disabled at the height of the attacks and many for a day or two after; some were continuously impaired in varying degrees between attacks.

TABLE II.-Incapacity

\begin{tabular}{|c|c|c|c|}
\hline Degree of Incapacity & & F. & M. \\
\hline $\begin{array}{l}\text { Impaired efficiency during attacks.. } \\
\text { Up to } 24 \text { hours a month in bed or off work } \\
1-3 \text { days } \\
4-6 \text { " } \\
\text { Total incapacity; had to give up work ", }\end{array}$ & $\begin{array}{l}\ldots \\
\cdots \\
\cdots \\
\ldots\end{array}$ & $\begin{array}{l}6 \\
4 \\
3 \\
3 \\
4\end{array}$ & $\frac{7}{6}$ \\
\hline
\end{tabular}

A greater number of women took time off work or, in the case of housewives, spent days in bed. The only man who had not worked for two years because of migraine had had a bad attendance record in previous years and also suffered from a compensation neurosis. Two men gave up working overtime, with consequent financial hardship. One classed under "impaired efficiency" occasionally took a week off work; another changed jobs frequently in the hope of finding one more suitable to his migraine. All four women who gave up work were married; one had not worked for eight years, though childless and keen to occupy herself ; a mother of two children gave up a responsible supervisor's post two years previously because of chronic invalidism but restarted part-time work while under our care ; another gave up a trying secretarial post in the City but recommenced similar employment in the suburbs, also under our care. One woman classed as taking two or three days off work a month had a spell of three months continuously off work the preceding year ; one classed under " impaired efficiency" had occasionally to spend a week in bed. Two of the women who had to have four to six days off work every month were unmarried; they were, respectively, a clerk and a civil servant. Most wives gave a history of their husbands having to do the housework during attacks.

In summary, five patients had to give up work; 17 lost an aggregate of over 400 working days a year, an 
average of nearly 25 days each; and 13 patients lost no time, but their efficiency was impaired during attacks.

\section{Previous Treatment}

All patients had received prolonged treatment with aspirin, codeine, barbiturates, and other analgesics, and all but three had had various ergot preparations singly or in combination. Three patients had received regular pethidine by mouth or injection, three antihistamine drugs, three had had hormone treatments, and two had had carbachol. In addition, three had attended a private migraine clinic for hormone and other drugs by injection, one attended a private school of relaxation, and one had had injection and later section of a supraorbital nerve. Other drugs given were "theobromine," amphetamines, and tranquillizers. Not infrequently the vehicle of administration of drugs was a suppository. This list is not exhaustive, because some patients had received drugs without being told either their name or nature.

Fifteen patients had previously been to 30 hospitals for their headaches. All had received medication for attacks as well as regular prophylactic medication in between. In some patients this had led to a drug habit. For example, one woman was taking daily at least $12 \mathrm{gr}$. $(0.78 \mathrm{~g}$.) of amylobarbitone sodium, 6-10 codeine co. tablets, 2-8 tablets of a proprietary ergot preparation, a proprietary ergot preparation by injection every two or three days, and at times other analgesic and tranquillizing drugs.

A number of patients were found to be obtaining drugs from more than one source-for example, from various chemists, doctors, and hospitals-with the result that no one doctor knew exactly what they were taking. Most patients thought large doses of drugs were having little or no effect but were afraid to stop them. Those who complained of severe persistent headache, depression, insomnia with drowsiness by day, inability to concentrate, poor memory, lack of energy, and lack of appetite, were often found to be taking large quantities of drugs. These patients also appeared to run from one attack of migraine to another without an intervening period of well-being.

\section{Psychiatric Investigation}

All patients were told that they were going to see a psychiatrist. Some were glad of the opportunity of talking about themselves and their troubles. Others, however, were upset because they took this to mean that the neurologist considered them psychiatric cases, with the result that initially they were on the defensive and tended to minimize or deny possible sources of emotional difficulties. In retrospect this difficulty could have been avoided had patients merely been told they were being referred to another doctor.

The psychiatrist's task was, however, made much easier, as formal histories had already been obtained and organic conditions excluded. Nevertheless another detailed history of migraine was taken, paying special attention to onset and times of exacerbation. This was followed by a detailed personal history, again paying special regard to dates and correlating exacerbations of migraine with disturbances in the patient's life. In this way attacks of migraine were gradually linked with emotional difficulties or upsets. Most patients had been unaware of any association even when it seemed obvious to them in retrospect, and certainly could not have related them before the psychotherapeutic interview.
Patients were then invited to talk about themselves freely with only such questions as "Tell me about your headaches " or "Tell me about yourself," the psychiatrist allowing the interview to be led by the patient. When it became clear that certain events or certain persons were associated with exacerbations, the patients were led back to discuss these and their emotional reactions either later in the same interview or as the starting-point of subsequent interviews. Most patients were seen two or three times in the first month for interviews lasting up to 45 minutes; psychotherapy was then continued at monthly or six-weekly follow-up visits. Some patients who at the first interview seemed trouble-free later came out with unsuspected troubles and difficulties. These also would not have been elucidated by direct questioning, since they had answered such questions as "Have you any worries?" at the first interview in the negative.

All gave the impression of having some disturbance or unhappiness in their lives. Since little would be gained by attaching formal diagnostic labels, it was thought simpler and more informative to grade patients by an assessment of degree of psychiatric disturbance. They were accordingly grouped into three categories: mild, moderate, and severe (see Table III). Those classed as mildly disturbed were primarily worried about their migraine ; those moderately disturbed were, in addition, anxious and depressed to a significant degree; those severely disturbed were agitated, were depressed, and had suicidal thoughts.

\begin{tabular}{|c|c|c|c|c|c|}
\hline \multicolumn{3}{|c|}{ Sex } & \multirow{2}{*}{$\begin{array}{c}\text { Mild } \\
8 \\
6\end{array}$} & \multirow{2}{*}{$\begin{array}{c}\text { Moderate } \\
9 \\
9\end{array}$} & \multirow{2}{*}{$\frac{\text { Severe }}{\frac{3}{-}}$} \\
\hline $\begin{array}{l}\text { Women } \\
\text { Men }\end{array}$ & $\begin{array}{l}\cdots \\
\cdots\end{array}$ & $\begin{array}{l}. \\
\cdots \\
\end{array}$ & & & \\
\hline & Total & .. & 14 & 18 & 3 \\
\hline
\end{tabular}

It is noteworthy that the three patients classed as severely disturbed were women. One of them had had previous psychiatric treatment for depression. All had ample psychiatric symptomatology which would have made them urgent cases for psychiatric treatment had they not been referred because of their presenting symptom, headache.

All patients were asked what they thought their headache was due to, or what illness they were afraid they might have and what they thought might happen if they were not relieved. A number thought at one time or another that they had serious disease, but fear of this had faded as time passed and they remained well apart from migraine. Of the 14 mildly disturbed patients, seven attributed their headache to migraine; four to "nerves"; one to overwork ; one to "worry, constipation, or excessive reading"; and one to an " inferiority complex." Of the 18 moderately disturbed patients, only three thought it was due to migraine; three thought it was due to "nerves"; one to catarrh ; one wondered whether he was going mad; another really thought he had damaged his brain by exceeding his mental capacity; three did not know, and the others were afraid they might have a "tumour," "cancer," "clot," or " cyst on the brain." All three seriously disturbed women thought they were going mad, and one also wondered whether her brain had been affected by atomic radiation. None had a conviction of disease amounting to a delusion. It seems, therefore, that as the degree of psychiatric disturbance mounted the more serious was the disease patients thought they had. 


\section{Psychological Factors}

During the course of the investigation it became apparent that psychological factors or emotional disturbance could influence the frequency and severity of migraine in three different ways.

In some patients the first attack followed an emotionally upsetting situation. In one woman this was the anniversary of her father's suicide by shooting himself through the head; another lost her father, sister, and uncle within a few months; in another the noise made by a fellow worker at her factory bench persisted in the patient's head and gradually developed into migraine. In one man the first migraine developed during a family crisis at the same time as he had to give up his life's ambition of a stage career.

Much more common was the finding of emotional difficulties as the background to persistent aggravation of already existing migraine. All the 16 married women had some domestic trouble which upset them. The patient whose husband was a transvestite and who had a backward child has already been mentioned; another was unhappy because her husband was on permanent night duty and left her with the management of a difficult son; the husband of another had chronic heart disease with temperamental changes; one husband was a sailor away for months at a time ; one frankly said it was her husband who ought to see the psychiatrist; one was an unsettled foreign girl married to a British soldier. Of the four unmarried women, two had always been shy and nervous, while two were frankly dissatisfied spinsters. Much the same circumstances were found among the men, with the addition of disappointments or annoyances at work.

In this connexion it is of interest that in a number of our patients, mostly men, attacks of migraine occurred only at week-ends while they were at home. One man described how his headaches had originally begun in this manner, then developed also when he went to the cinema or on long drives with his wife, and thereafter occurred nightly but always cleared up in the morning by the time he reached his office. This tallies with the experience of two other patients who to their surprise were free from attacks during the war. One was a woman whose husband served abroad throughout ; and the other a married man who was free from headaches for the five years he was an officer in a fighting regiment.

The third way in which psychological factors seemed to act was that in established migrainous subjects they precipitated a series of attacks. This was more obvious among the men. One developed an exacerbation when told his child was a mongol; another when he was rejected for the Services; a third during a period of excessive work for his trade union; another in relation to accountancy examinations ; another during his wife's pregnancy; and a childless woman when she lost her pet dog. One patient described it graphically: " My mother died, my daughter went to Canada, my husband lost his teeth, and my boy changed to ladies' hairdressing, all in one month."

At least two-thirds of the patients volunteered that their migraine was made worse by worry, fright, annoyance, rows, or other upsets ; some said excessive work or "too much thinking" brought on attacks. Holidays and festive seasons sometimes had the same effect. Some developed exacerbations when they heard of serious illness or death in a friend or relative and were then inclined to think they had similar trouble. This led to a number of recurrences after an initial period of improvement. Anniversary times seemed to play a part in some exacerbations: three patients attended 10 years after they had lost a favourite parent, and three who were unhappily married had been so for 10 years. In four of these six the anniversary coincided not only with the year but also the month and almost the day of attendance.

In several patients with a positive family history it seemed that their migraine might not have been hereditary but rather acquired through early imitation or identification with a sufferer close to them.

\section{Intelligence and Personality}

The intelligence of our patients, roughly assessed, varied as widely as their occupations and bore no relation to severity of migraine. Though anxiety and depression were common, obsessional features seemed no more apparent than in any other group of patients. A few of our patients laboured under disappointed hopes or thwarted ambitions, but, if anything, attacks seemed related to unhappiness and annoyance in their emotional relations rather than to result from disturbing or faulty personality factors in their make-up.

\section{Results of Treatment}

The natural history of migraine, with its variations and the many unaccountable factors by which it may be influenced, makes assessment of results of the treatment difficult. We therefore avoid the word "cure," particularly as it became clear during the course of this work that some patients remained liable to relapse as the result of an untoward event, though they became less susceptible and tended to get over exacerbations more easily and quickly. In order to minimize observer error and therapeutic bias, both regarding migraine and psychiatric disturbance, we assessed all patients independently. Allowance was also made for the fact that some patients may desire to please the doctor by minimizing symptoms, while others are reluctant to admit improvement when this occurs in the absence of any physical therapies.

Assessment of improvement of migraine was based on frequency, severity, and duration of headache, incidence of vomiting and visual disturbance, degree of incapacity during attacks, and diminution of drug intake. The assessment of psychiatric improvement was based on lessening or disappearance of anxiety and depression. In each of these aspects improvement was assessed as no change, mild to moderate, and marked. In $80 \%$ of patients our assessments agreed, while in the remainder our differences were slight and evened out. Our aim was limited to helping patients sufficiently to lead normal lives in which they could endure infrequent beadaches without incapacity, without becoming anxious or depressed, without interval medication, and only minimal, if any, medication during attacks.

\begin{tabular}{|c|c|c|c|c|}
\hline Improvement & & Migraine & Psychiatric & Drug Reduction \\
\hline $\begin{array}{l}\text { Unchanged } \\
\text { Mild-moderate } \\
\text { Marked }\end{array}$ & $\begin{array}{l}. . \\
.\end{array}$ & $\begin{aligned} 2 \\
16 \\
17\end{aligned}$ & $\begin{array}{r}5 \\
15 \\
15\end{array}$ & $\begin{array}{l}1 \\
15 \\
19\end{array}$ \\
\hline
\end{tabular}


Table IV shows that in $94 \%$ there was a significant improvement in migraine, in $86 \%$ in psychiatric disturbance, and in $97 \%$ a significant reduction of drug intake.

"Mild-moderate" improvement of migraine meant that attacks were reduced in frequency and severity up to four a month, causing little distress, with freedom between and improved working capacity. Those markedly improved still had occasional migrainenever more than once or twice a month-which was milder, of shorter duration, and had little or no effect on working capacity ; there were also prolonged periods of freedom in which they were well.

Improvement was further assessed by recording the drugs that patients were taking before and after attending. In Table IV the group labelled " mildmoderate reduction in drugs" mostly stopped taking tablets to prevent headaches but continued much the same medication for attacks; as these, however, had diminished both in frequency and in severity they were, in fact, taking fewer tablets than before. A " marked" reduction meant that patients were taking no medication between attacks and only a little aspirin, codeine, or ergotamine during them. A few were able to stop all tablets. The most impressive feature was the overall reduction of interval medication. No relation was observed between duration of migraine and therapeutic result.

Six patients relapsed after initial improvement, in each case after an identifiable distressing event, and improved again later. Eighteen patients remain under two to three monthly observation and have now attended for 18 to 24 months.

\section{Discussion}

Though unselected for the National Hospital, these patients were naturally selected by having been referred to a specialist. centre because they were severely incapacitated by frequent attacks uncontrolled by the standard drug treatments or because they were severely disturbed by their attacks. They cannot, therefore, be considered representative of the migraine population as a whole.

The common organic diseases alleged to aggravate or even cause migraine were so infrequent as to suggest that they were incidental. On the other hand, all our patients showed evidence of psychiatric disturbance and many appear to have been helped by simple psychotherapy. Though it is usually assumed that psychiatric illness associated with migraine is due to the migraine, and therefore to cure the migraine is to eliminate the psychiatric disturbance, our results show the reversenamely, that frequency and severity of attacks may be influenced for better or for worse by psychological factors. It seems almost as if it was more important to ask patients "Who or what is your headache?" rather than "When or where?" Improvement was not related to new ar additional drugs, since none were given; indeed, the best results were obtained in those who finally took minimal or no drugs at all, even during attacks. Patients reduced drugs partly on our advice, and partly as they noticed improvement. It appeared that excess drugs were making some patients worse since all who said they were never entirely free from headache as well as having frequent migraine were in fact taking large quantities. In some patients drugtaking had become a habit, even to the point of addiction, and migrainous symptoms became mixed up with the side-effects of drugs. In many patients a reduction in total drug intake resulted in drugs that had ceased to control migraine attacks regaining their earlier therapeutic effect.

Results of psychotherapy must be assessed against the beneficial effect resulting from the mere fact of visiting a hospital, giving a detailed history, being fully examined, and having fears of serious illness allayed. In addition the interest shown by two doctors concurrently and repeatedly doubtless played a part. In five cases improvement seemed to be related to events in the patients' lives unconnected with our endeavours. For instance, one patient's husband developed a mediastinal tumour; another's mother-in-law died suddenly. Both reported these facts and improvement at the same interview. The third patient improved when rejected by an Army Medical Board; the fourth on becoming pregnant; and the fifth when he developed a gastric ulcer. Another patient improved because, as he said, he realized that there could be nothing the matter with him because we were not giving him any treatment, so there was no need for him to have headaches.

Even those patients classed as not improved ceased to deteriorate, nor did drug intake increase or migraine incapacity become worse. In a few patients it was felt that no major improvement could be expected until they had relinquished their drug habits. Two patients could not be helped.

\section{Summary}

A group of 35 patients suffering from migraine in whom standard remedies had failed were studied physically and psychiatrically and treated by psychotherapy. Followed up at 6-12 months, the majority had improved, with reduction of headaches, psychiatric disturbance, drug intake, and incapacity.

It is concluded that in this group of migraine patients psychological or emotional factors played an important part in aggravating the frequency and severity of attacks.

We thank the physicians of the National Hospital, Queen Square, for access to case notes and permission to publish.

The National Library of Medicine possesses a draft of a letter by John Shaw Billings, dated August 26, 1887, to the Boston sculptor, Truman H. Bartlett. Mr. Bartlett was extremely interested in the relationship between Abraham Lincoln's physical characteristics and his mental and moral powers, and in the summer of 1887 he requested Billings" opinion on the matter. Billings points out that "one of the sharacteristics of Mr. Lincoln's physical structure was the small proportion of the vascular and glandular systems, including the blood vessels and lymphatics, as compared with the bones and muscles." His metabolism, Billings added, was slow, but he believed that such considerations covered "but a very small part of Mr. Lincoln's characteristics. There are thousands of men in this country whose ancestry and early surroundings were similar to his, whose immediate ancestors had been exposed to malarial influences-whose food had been fried pork, saleratus bread, etc., and who are the tougher survivors of this sort of bringing up, and who are tall, lean, sallow, with harsh, dry skins, etc. ..." W. H. Herndon, replying to another letter from Bartlett on the same subject, terms the "pork and miasmatic" theories guesswork; he calls physicians theoretical above all classes of men, refuses to surrender facts for theories, and maintains that Lincoln "had a fine network of nerve under the coarse flesh." (U.S. National Library of Medicine News, February, 1960.) 